\title{
A GESTÃO PATRIMONIAL NA ADMINISTRAÇÃO PÚBLICA
}

\author{
ASSET MANAGEMENT IN PUBLIC ADMINISTRATION
}

\section{Renato Alencar de Moraes $^{1}$}

RESUMO: O objetivo deste artigo é estudar o controle patrimonial dos bens na administração pública como um instrumento de Governança Pública. Como finalidades peculiares procurou-se entender os fundamentos da Administração Pública e delinear as metodologias, tecnologias e os recursos instituídos no controle patrimonial pelo ente Público. Por serem reservados ao suporte de um interesse coletivo os recursos públicos necessitam ser governados de modo a potencializar os direitos à sociedade considerando os preceitos constitucionais da legalidade, impessoalidade, moralidade, publicidade e eficiência. Em relação às ações administrativas jamais se obstem desta ligação foram constituídos os instrumentos de controle interno e externo. O controle patrimonial é um tipo de controle interno que comporta a gerenciamento de informações atualizadas sobre dos bens públicos duráveis assim como, as informações sobre a aquisição responsável pela carga patrimonial e os documentos de baixa patrimonial.

Palavras-chave: Gestão Patrimonial - Controle - Administração Pública

ABSTRACT: The aim of this paper is to study the patrimonial control of assets in public administration as an instrument of public governance. As peculiar purposes we tried to understand the fundamentals of Public Administration and to outline the methodologies, technologies and resources instituted in the patrimonial control by the Public Entity. Because public resources are reserved for the support of a collective interest, they need to be governed in such a way as to enhance the rights of society considering the constitutional precepts of legality, impersonality, morality, publicity and efficiency. Regarding administrative actions, this connection was never obeyed and internal and external control instruments were constituted. Asset control is a type of internal control that includes the management of up-to-date information on durable public goods as well as information about the acquisition responsible for the asset load and low-asset documents. 
Keyword: Property Management - Control - Public Administration

\section{INTRODUÇÃO}

O presente estudo, buscaremos fazer uma análise sobre a gestão patrimonial na administração pública. Este estudo visa evidenciar a importância de se realizar a administração patrimonial dos bens permanentes em órgãos relacionadas à administração pública, por meio do emprego de ferramentas institucionais de maneira que forme recursos públicos e espelhe conforme as regras legais a disposição patrimonial física.

Quando desempenhado devidamente esta gestão assegura os benefícios especificamente ligados a qualquer planejamento de controle, assim como a prevenção das penalidades aplicadas aos gestores que se recusem cumprir esse o dever de zelar pelas contas públicas.

O controle patrimonial corresponde um conjunto dos bens móveis, equipamentos e outros classificados como material permanente. O patrimônio necessita de controle que o compreende, incorporação que se dá aos bens adquiridos por compra comodato, doação, movimentação que pode ser interna, quando é imprescindível o registro no sistema de patrimônio para garantir o controle físico, externa que se refere a toda e qualquer movimentação externa, para tanto, se requer autorização formal da autoridade competente, baixa quando das alienações por venda, doação ou permuta, sinistros por furto e roubo.

O controle é feito com base em leis federais, estaduais e normas internas dos órgãos ou entidades, além dos responsáveis, pelo controle interno e externo. As leis federais 8.666/93, 4.320/64 e LC IoI/2000, com as publicações das portarias do tesouro nacional que dispõe sobre o setor de patrimônio encarregado do controle de bens do patrimônio público, deverão ser responsáveis por muito mais tarefas do que o simples controle físico dos bens e sua localização.

A gestão patrimonial permite controlar e gerar informações fundamentais sobre o ativo imobilizado, possibilitando saber qual é o patrimônio real da empresa, onde estão localizadas, as características principais, durabilidade, vida útil, total e remanescente dos 
bens. Permite ainda o controle do sistema integrado de administração de pessoal, o registro de alterações cadastrais nos bens e a geração dos registros do sped Fiscal. Com advento da Lei II.638/o7, CPC or e CPC 27, a gestão patrimonial não é apenas mais uma obrigação burocrática de controlar os bens do ativo imobilizado, é de responsabilidade da instituição, assegurar a veracidade das informações sobre os ativos e a situação contábil da administração pública.

A compreensão adequada dos princípios da gestão patrimonial carece da familiarização com uma série de conceitos, desde apresentação de um material permanente ao material de duração superior a dois anos, levando-se em consideração os aspectos de durabilidade, fragilidade, perecibilidade incorporabilidade e transformabilidade, instalações, materiais ou equipamentos que se agregam ao bem público, isoladamente ou em conjunto, passando a integral a funcionalmente.

A finalidade principal deste estudo é compreendida através da argumentação da forma mais correta a ser dispensada aos bens permanentes obtidos pelos órgãos da administração pública, com fundamento na Lei 4.320/64 e em suas alterações, do mesmo modo que as legislações complementares em vigor atribuída ao controle patrimonial.

\section{CONCEITO DE PATRIMÔNIO PÚBLICO}

Duarte Júnior (2006, p. 26) conceitua patrimônio consistindo "o conjunto de bens avaliados em dinheiro, relacionando-se simultaneamente às esferas da natureza, da genética, da economia, da nação e também, como não poderia deixar de ser, à da cultura”. Costa (2oII, p. 28) abrange patrimônio como sendo: “a empresa do ser humano relacionado à tríade arte/memória coletiva/repasse de saberes, protegida pelo direito, tendo em vista o princípio constitucional da dignidade, tanto do universo humano, quanto dos indivíduos, ligada à ideia emancipatória de desenvolvimento".

O conceito se estende quando o patrimônio passa a ser imaterial, cultural, urbanístico, paisagístico, social e natural, ou seja, são múltiplos conceitos de patrimônio para 
que se possa entender riqueza como bem pública que deve ser usado com sustentabilidade e respeitado como coisa material ou imaterial (ELIAS, 1994).

O conceito se alarga pela forma da transformação do Estado e na sua descentralização frente à sociedade regional de uma cidade, tendo como agente público mais próximo à figura do prefeito, que representará o Executivo frente às altas esferas hierárquicas governamentais, para um excelente planejamento para sua cidade. Ademais será a figura desse gestor que qualificará as políticas públicas e sociais, numa perspectiva de atendimento público vivenciado nos moldes das necessidades perenes da população.

Sob a ótica da citação anterior, vê-se claramente o necessário esboço da possibilidade de aplicação e eficácia real do estudo da permanência da Administração Pública Municipal que poderá gerir com mais ênfase e suporte, na solução de todos os problemas que uma cidade enfrenta, inclusive, aspectos políticos, privados e públicos (ELIAS, 1994). Como bem salientou Miguel de Serpa Lopes (1996), a violação de um direito gera a responsabilidade em relação ao que a perpetrou.

Todo ato executado ou omitido em desobediência a uma norma jurídica, contendo um preceito de proibição ou de ordem, representa uma injúria privada ou uma injúria pública, conforme a natureza dos interesses afetados, se individuais ou coletivos. Tal ditame propicia conceitos desastrosos ao patrimônio quando este é desobedecido

Por fim, o conceito de patrimônio só terá vigor eficiente quando o Estado tomar conta da coisa pública. Com o desenvolvimento do Estado, em especial nas prestações de serviço público adequado e de qualidade para a proteção do patrimônio, surgiu o princípio da descentralização, que visa à transferência de algumas funções do Estado para outras pessoas jurídicas.

Destina-se a facilitar a execução dos objetivos do Estado na segurança do patrimônio de uma cidade, para que haja eficiência técnica, jurídica e financeira no desempenho de suas funções, propiciando ao serviço de segurança pública ao patrimônio zelado.

A descentralização, contemporaneamente, não se dá apenas com a criação de autarquias tradicionais ou entidades paraestatais, mas sim com a transferência, pelo Estado, 
principalmente o poder municipal, do dever de execução de uma atividade a terceiros estranhos à estrutura da administração pública.

A importância do tema amplia-se à medida que, se de um lado tem-se a intensificação do Estado, vinculado à inteligência ambiental e do outro lado numa capital como Florianópolis os bens públicos devem ser amplamente estados (SERPA LOPES, 1996).

\section{I Conceito de bem público conforme o Código Civil}

O tema relacionado aos bens jurídicos em geral é tratado no Código Civil, que dedica um capítulo aos bens públicos e particulares. A regra básica encontra-se no artigo 98 que trás o conceito de bem público, como podemos analisar abaixo:

\section{CAPÍTULO III}

Dos Bens Públicos

Art. 98. São públicos os bens do domínio nacional pertencentes às pessoas jurídicas de direito público interno; todos os outros são particulares, seja qual for a pessoa a que pertencerem.

Art. 99. São bens públicos:

I - os de uso comum do povo, tais como rios, mares, estradas, ruas e praças;

II - os de uso especial, tais como edifícios ou terrenos destinados a serviço ou estabelecimento da administração federal, estadual, territorial ou municipal, inclusive os de suas autarquias;

III - os dominicais, que constituem o patrimônio das pessoas jurídicas de direito público, como objeto de direito pessoal, ou real, de cada uma dessas entidades.

Parágrafo único. Não dispondo a lei em contrário, consideram-se dominicais os bens pertencentes às pessoas jurídicas de direito público a que se tenha dado estrutura de direito privado.

Art. ıoo. Os bens públicos de uso comum do povo e os de uso especial são inalienáveis, enquanto conservarem a sua qualificação, na forma que a lei determinar.

Art. ror. Os bens públicos dominicais podem ser alienados, observadas as exigências da lei.

Art. I02. Os bens públicos não estão sujeitos a usucapião. 
Art. 103. O uso comum dos bens públicos pode ser gratuito ou retribuído, conforme for estabelecido legalmente pela entidade a cuja administração pertencerem. (BRASIL, 2002).

Celso Antônio Bandeira de Mello conceitua a definição de bem público de uma maneira mais ampla, é aquele que acertado a prestação de serviço público. José dos Santos Carvalho Filho (2013, p. I.157) trás o entendimento sobre o conceito de bens públicos in verbis:

Com base no vivente dispositivo do novo Código Civil, podemos então, conceituar
bens públicos como todo aqueles, de qualquer natureza e a qualquer título,
pertençam as pessoas jurídicas de direito público, peso elas federativas, como a
união, os estados, o Distrito Federal e os municípios , administração
descentralizada como as autarquias, incluindo-se as Fundações público e
associações públicas.

A classificação do bem público quanto à destinação pode ser um bem de uso comum do povo ou de domínio público. A classificação do bem de uso comum do povo é aquele utilizado livremente pela população, ou seja, são aqueles bens que não necessita de autorização, mas podem sofrem alguma regulamentação.

O poder público pode regulamentar, por exemplo, o poder público pode regulamentar 609 a utilização de praças e também de estradas e rios, mas como regra a utilização de bens de uso comum são aqueles que todas as pessoas podem utilizar de forma livremente. Bens de uso comum não admitem exclusividades e também privilégio

Já os bens de uso especial, o nome já ajuda, visto que são bens utilizados de forma especial pelo poder público, ou utilizados estabelecimento dos entes públicos para prestação de um serviço público. A repartição de um órgão público, por exemplo, é um bem especial, automóvel também é um bem público, o cemitério público é considerado um bem de uso especial.

O bem de uso especial possui uma destinação a uma situação específica. Importante ressaltar que as terras indígenas são consideradas como bem de uso especial, porque tem como finalidade específica que é a preservação da cultura indígena, sendo considerada para doutrina como bem especial de uso indireto, da mesma forma a doutrina trás como bem de uso especial terras de reserva ambiental. 
Bens de uso comum e bens de uso especial são bens afetados a finalidade pública. No entanto, os bens dominicais são bens desafetados, ou seja, bens desafetados não tem destinação não servem de estabelecimento. São aqueles de uso comum do povo, por exemplo, móveis inservíveis, prédios desativados, a doutrina trás os terrenos de marinha. Os bens dominicais incorporam ao patrimônio da pessoa jurídica de direito público, mas eles não têm uma destinação específica, sendo alienáveis.

O Código Civil no artigo ıoo, trás as algumas características sobre o bem de uso comum do povo e bens especiais que são inalienáveis, enquanto conservarem a sua qualificação, na forma que a lei determinar. Isto é esses bens podem ser alienadas observadas as exigências da lei e bens públicos não está sujeitos à usucapião.

Algumas características do bem público quais são imprescritibilidade impenhorabilidade, inalienabilidade e não onerabilidade, todos os bens públicos de uso comum são especiais ou os dominicais são imprescritíveis. $O$ que significa que não podem ser adquiridos por usucapião. A Constituição Federal de 1988 em seu artigo 183 \$3ำ e artigo I9I parágrafo único estabelece a mesma redação para os dois dispositivos: "os imóveis públicos não serão adquiridos por usucapião”. (BRASIL, I988).

Com a finalidade de reforçar esses artigos constitucionais, o Supremo Tribunal Federal pacificou o tema, através da súmula 340, "Desde a vigência do Código Civil, os bens dominicais, como os demais bens públicos, não podem ser adquiridos por usucapião”. (STF, 1963), ou seja, todos os bens públicos são imprescritíveis não podendo ser adquiridos de usucapião não existindo nenhuma exceção, seja bem especial, comum e dominical.

A Constituição Federal nos artigos 183, § $3^{\circ}$ e 19I, parágrafo único, preconiza a impossibilidade de se usucapir qualquer espécie de bem público, seja de uso comum do povo, de uso especial ou dominical, mesmo na hipótese de usucapião urbano ou rural constitucional para moradia própria ou da família ou pro labore. O Tribunal de Santa Catarina também aplica a imprescritibilidade dos bens públicos, como podemos observar o entendimento do Pedro Aujor Furtado Júnior: 


\begin{abstract}
Bens públicos, como são as áreas verdes de loteamentos destinadas ao ente municipal, são insuscetíveis de ocupação, posse ou usucapião por parte de particular. Na hipótese de esbulho, cabe ao Município o direito à reintegração de posse com a retirada de toda e qualquer benfeitoria que lá tenha sido feita, não tendo o precário detentor qualquer direito a proteção possessória, indenização de benfeitorias ou retenção, porque não age de boa-fé, sabendo que o imóvel pertence à municipalidade. É inarredável a impossibilidade de bens públicos, sejam de uso comum do povo, de uso especial ou dominicais, tornarem-se objeto de aquisição por usucapião, ex vi do disposto nos artigos I83, § $3^{\circ}$, e 191, da Constituição Federal, e ro2 do Código Civil, e da Súmula 340 do Supremo Tribunal Federal. (TJ-SC, 2019, on-line)
\end{abstract}

Conforme discorre o artigo I02 do Código Civil que os bens públicos, móveis ou imóveis, não estão sujeitos a usucapião, eis que existe a imprescritibilidade das pretensões a

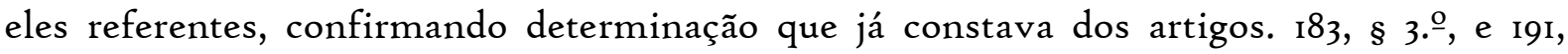
parágrafo único, Constituição Cidadã, quanto aos bens imóveis. A expressão contida no dispositivo legal engloba tanto os bens de uso comum do povo como os de uso especial e dominicais.

O instituto da imprescritibilidade dos bens públicos surge como efeito lógico da inalienabilidade originária. Se os bens púbicos são originariamente inalienáveis, segue-se que ninguém os pode adquirir enquanto guardarem essa condição. Sendo não ser possível a invocação de usucapião sobre eles. Visa o princípio jurídico, de aceitação universal, que não existe direito contra direito, isto é, não se adquire direito em desconformidade com o direito.

Como se pode verificar, o ente municipal detém a propriedade e a posse jurídica do imóvel em questão, caso em que o apelante somente poderia exercer legitimamente a posse, mediante autorização, concessão ou permissão da Administração Pública, hipóteses não verificadas no caso em exame, sobretudo porque, o recorrente invadiu a área pública de loteamento urbano, para interesse próprio, de modo que sua ocupação constituiu esbulho. Ademais, a consolidada jurisprudência do Superior Tribunal de Justiça é firme no sentido de não ser possível a posse de bem público, constituindo a sua ocupação, quando autorizada, mera detenção de natureza precária, e a invasão constitui esbulho. 
Os bens públicos são impenhoráveis, isto é, não pode ser penhorado não podendo sofrer nenhuma constrição judicial. Poder Público, paga algum tipo de divida através de precatório. Atenção as estatais, empresa pública e sociedade de economia mista tem essa característica enquanto prestador de serviço público. Se tiver realizando eminentemente uma atividade econômica a impenhorabilidade não é aplicada. Entendimento discordado pelo mestre José dos Santos Carvalho Filho. (2013, p. I.159).

[...] os bens das pessoas administrativas privadas, como é o caso das empresas públicas, sociedade de economia mista, e fundações públicas de direito privado, devem ser caracterizados com bens privados, mesmo que em certos casos a extinção dessas entidades possa acarretar o retorno dos bens ao patrimônio da pessoa de direito público de onde se haviam originado. $O$ fator que deve preponderar na referida classificação é o de entidades têm personalidade jurídica de direito privado e embora vinculadas a administração direta, atuam normalmente com a maleabilidade própria das pessoas privadas. Aliás, não custa lembrar a Lei n. $6404 / 76$, que dispõe sobre as sociedades anônimas, previa expressamente no artigo 242, que os bens de sociedade economia mista sujeitavam-se normalmente ao processo de execução e penhora de seus bens, o que indica claramente que não se poderia mesmo tratar de bens públicos, haja vista que uma das características destes é exatamente a impenhorabilidade. Apesar de o dispositivo tem sido revogado pela lei 10.303/2001, ou preceito nele contido subsiste normalmente, já que inexiste qualquer comando constitucional que autorize a extensão da qualidade de bens públicos aos referidos bens.

Além da imprescritibilidade e da impenhorabilidade a inalienabilidade, como regra os bens públicos são inalienáveis, porém os dominicais podem ser alienados porque estes não tem uma afetação pública, são bens desafetados podem ser alienados observados os devidos procedimentos legais. Para ser alienado, o bem dominical precisa que o bem esteja esta desafetado, necessita da avaliação prévia, autorização legislativa e procedimento licitatório.

A inalienabilidade é regra em relação aos bens comuns e especial, sendo a exceção a esta regra aos bens de uso dominical, que neste caso, poderá ser utilizada o emprego da alienação desde que obedeça aos requisitos legais. A posse pode ser protegida como um fim em si mesma, exercendo o particular o poder fático sobre a res e garantindo sua função 
social, sendo que o critério para aferir se há posse ou detenção não é o estrutural e sim o funcional.

É a afetação do bem a uma finalidade pública que dirá se pode ou não ser objeto de atos possessórias por um particular. A última característica dos bens públicos, que estes não podem ser onerados, não podendo ser dados em garantia. Não podendo usar o bem público a título de fazer um penhor, uma hipoteca e até mesmo anticrese. Sendo essa característica imposta a todos os bens públicos, sendo o que é relativizado é a inalienabilidade, porque os dominicais podem ser alienados respeitados os devidos processos legais.

\section{GESTÃO PATRIMÔNIAL NA ADMINISTRAÇÃO PÚBLICA}

Com a diversidade e do crescimento na disciplina da administração, no âmbito público tal como no âmbito privado progressivamente revelam-se ferramentas convenientes de transpor com mais eficiência e garantir maiores consequências nos processos administrativos institucionais.

Essas ferramentas são bem aceito no presente quadro político e econômico no país, em que se verteu fundamental a adesão de toda nova maneira de gerenciar os órgãos públicos, garantindo mais responsabilidade, celeridade e clareza com a finalidade em obedecer aos interesses da sociedade.

O sistema jurídico brasileiro classifica o controle como uma ferramenta eficiente de gestão administrativa. Dornelles (2009) agrega a definição, como um conjunto de procedimentos, de métodos e de rotinas que têm, como principal foco, proteger o acervo patrimonial e agregar qualidade à gestão através de ações preventivas que compreendam planejamento e avaliação periódica da atuação administrativa, dentro da mais absoluta legalidade. 
A Constituição Cidadã em seu artigo 74 indica que cada poder possui o seu sistema de controle interno. Nesse caso, seus responsáveis possuem responsabilidade solidária, em virtude de evitarem atribuir conhecimento ao Tribunal de Contas na presença de qualquer desvio poderão sofrer responsabilidades civil ou penalmente. Logo as pessoas da administração pública direta e indireta necessitam contar um sistema de controle interno.

Art. 74. Os Poderes Legislativo, Executivo e Judiciário manterão, de forma integrada, sistema de controle interno com a finalidade de:

I - avaliar o cumprimento das metas previstas no plano plurianual, a execução dos programas de governo e dos orçamentos da União;

II - comprovar a legalidade e avaliar os resultados, quanto à eficácia e eficiência, da gestão orçamentária, financeira e patrimonial nos órgãos e entidades da administração federal, bem como da aplicação de recursos públicos por entidades de direito privado;

III - exercer o controle das operações de crédito, avais e garantias, bem como dos direitos e haveres da União;

IV - apoiar o controle externo no exercício de sua missão institucional.

§ Iㅇ Os responsáveis pelo controle interno, ao tomarem conhecimento de qualquer irregularidade ou ilegalidade, dela darão ciência ao Tribunal de Contas da União, sob pena de responsabilidade solidária.

§ 2ำ Qualquer cidadão, partido político, associação ou sindicato é parte legítima para, na forma da lei, denunciar irregularidades ou ilegalidades perante o Tribunal de Contas da União. (BRASIL, I988).

O controle interno, como o conceito define serve para controlar a conclusão orçamental patrimonial, ativo financeiro e contábil das instituições objetivando à consonância com as legislações e ao harmonia das contas públicas, que necessitam primar nos órgãos públicos, formando prerrogativa ao exame real de direções públicas do País.

Com o advento da Lei de Responsabilidade Fiscal o legislador percebeu a necessidade de uma lei que regulasse a gestão sobre o patrimônio público e resolveu dedicar um capítulo integral sobre esse tema. Através da aprovação e posterior publicação o processo de administração financeira, orçamentária, patrimonial e contábil operado pela União e pelos 
Estados brasileiros que logo demonstraram sua precaução com o patrimônio público, requisitando dos órgãos da administração direta e indireta um explicação melhor da destinação dos bens da administração pública.

O controle que faz parte da gestão patrimonial, parte integrante do controle interno, ao passo que assegura a execução de normas técnicas, administrativas e legais. É exercido o tratamento da devida gestão patrimonial na administração pública e de seus benefícios incluindo elementos de lançamento e de controle dos patrimônios públicos, sejam estes, imóveis e móveis, além das penalidades inseridas no sistema jurídico se por ventura a instituição não obedecer a essa norma.

O patrimônio é o conteúdo governado que segue para permitir às instituições a conquista de suas finalidades. Para que um patrimônio deve obedecer às disposições: a matéria deve ser associada a um quadro que haja significado financeiro e avaliado em moeda. Autonomia dos elementos integrantes do patrimônio e ingresso do quadro a uma instituição que aponte a conquistar determinados resultados.

O patrimônio público, para Torres e Silva (2003), é composto por bens de toda natureza e espécie que tenham interesse para a administração pública e para a comunidade administrada. No entanto, para Kohama (200I, p. 213), patrimônio público é nada mais que o conjunto de bens, direitos e obrigações, avaliados em moeda corrente, das entidades que compõem a administração pública.

O controle patrimonial integra em execuções que confirmam através declarações e avaliações, a colheita de informações, essenciais ao reconhecimento, existência, volume instalação status de utilidade e memorial dos bens patrimoniais, começar a sua primeira inserção no patrimônio, até a sua baixa final. O emprego de controle patrimonial terá de ser empregada pela fração de patrimônio, concede a esta regular como uma associação de referências dos bens corpóreos.

O controle renova as informações de registro e gera diariamente o quadro geral dos bens. Através da gestão e do controle, examina os atos retroativo e os atos atuais assim como 
se organizam fundamentos de ação para o futuro. Por instrumento do controle, propõem-se as examinações periódicas, a fixação de tombamento dos bens móveis, e supervisiona qualquer a transferência dos bens ao durante a sua vida útil.

\section{I Procedimentos de controle patrimonial}

Os bens patrimoniais, devido à utilização e pela deterioração proveniente durante o tempo, sofrem diminuição de correspondente valor real que se intitula depreciação, identificada na legislação quanto à depreciação do valor dos patrimônios materiais ou imateriais por corrosões por perda de utilidade por uso, por atos da natureza ou por redução da vida útil.

O cálculo da depreciação é realizado um estudo na divisão do valor contábil pelo período de vida útil do patrimônio, analisando a introdução no valor contábil e no valor da conta de depreciação e os valores oriundos de reavaliações, conforme a obediência do artigo I48, inciso V da Lei Federal n ${ }^{\circ} 4 \cdot 320 / 64$.

Este processo deve ser realizado todos os anos pelas entidades, alterando o valor de toda unidade do patrimônio, calculando para integrar no inventário anual. E o valor do bem depreciado acumulado, conforme sujeitada à revisão monetária, de modo nenhum podendo transcender o valor do preço do bem e a devida correção monetária.

Os bens da administração pública devem passar pelo inventário periodicamente, ou seja, tem que possuir uma relação atualizada do patrimônio. Administração pública é obrigada encontrar o valor justo, isto é, o valor de mercado desses bens que estão inventariadas.

Outra obrigação importante é avaliação dos bens móveis e imóveis, pode ser de dois tipos, o primeiro é a reavaliação, ou seja, o valor contábil na peça balanço patrimonial está 
defasado, então tem a necessidade de se fazer uma estimativa maior, nada mais é do que reavaliar, ficando o balanço patrimonial com mais crédito, gerando uma variação patrimonial aumentativa ao contrário se faz o implement, o valor contábil, está a maior no balanço, então não se deve diminuir, fazendo um lançamento numa VPD (Variação Patrimonial Diminutiva).

E o último procedimento é a realização do lançamento da depreciação amortização ou exaustão, fazer a contabilização do consumo do bem móvel ou imóvel no decorrer dos períodos mensais, é a depreciação até o momento e quem se tenha o valor final que é o valor é justo daquele bem e que será a contabilização final escriturado no balanço patrimonial.

A reavaliação a técnica de atualização dos valores dos bens de uma entidade, através da análise do custo do negócio, embasada em opiniões técnicas, mediante pareceres em que a diversidade entre o valor original constante e o valor reexaminado deve ser anotada no patrimônio.

A Lei 4.320/64 concede que se aja à reavaliação dos bens móveis e imóveis, processo este que, disposto devidamente torna mais objetivo o valor do bem público. No decorrer da composição dos inventários, uma das ações importantes é a análise dos elementos integrantes do patrimônio, que se faz pelo valor de obtenção de constituição ou de rendimento para os bens móveis e imóveis ou de provisões industriais, ressaltando que, depois da publicação da lei que estabeleceu normas de direito financeiro para elaboração e controle dos orçamentos e balanços a reavaliação tornou-se obrigatória.

\subsection{Teoria da Agência e os mecanismos de controle}

Devido a Revolução Industrial, fabricações que anteriormente eram geridas propriamente por seus donos são substituídas por grandes empresas criadas com o capital de uma diversidade de investidores. Com tal característica a diversidade da administração carece a admissão de geradores com habilidades para exercer em nome dos sócios. 
Nesse quadro ocorrem duas classes com interesses contrários donos do capital que pretendem potencializar seus resultados e gestores empregados que esperam boas renumerações e outros incentivos.

Uma relação de escritório pode ser marcada como um pacto entre agentes e principais, sendo a transferência de poder de deliberação ao agente por parte do principal. Não obstante surge uma alta aptidão de melhoramento de resultados pelos agentes em relação dos interesses do principal.

O tema principal em que se estão os discussões de agência é a organismo da assimetria de comunicados entre os agentes e os principais, o que é capaz esperar medidas incertas ou a tentativa de farsas Grande parte das atividades é materializada em um panorama com oscilação informacional, dado que pelo menos uma das partes foca mais participações em rol à outra.

A título de exemplo um vendedor entende melhor o produto vendido do que o consumidor e será capaz lograr ganhos por causa desta a assimetria.

A formação de ferramentas de acompanhamento das ações desenvolvidas pelos agentes conta uma matriz de coibir descuidos e concede aos sócios o rastreamento de informações sobre as atividades Mas esses instrumentos podem configurar despesas notáveis para o principal, os quais são intitulados de esforços de escritório.

No setor público o disputa de interesses é bem normal e se evidencia especialmente pela corrupção de servidores e políticos os quais desprezam a finalidade pública e visam seus esforços para a alcance de benefícios improprias ou lascivos transgredindo os argumentos políticos e os encargos adquiridos em relação a posse. 


\subsection{Controle da Administração Pública Brasileira}

A presença do Estado como instituição congruente ordenada por normas criadas pela soberania popular e com entidades regulares carece dos instrumentos de controle para a sua manutenção Os instrumentos de controle são essenciais para a essência do Estado.

O monitoramento que incide sobre a Administração Pública integra na inspeção das funções elaboradas pelos agentes públicos, a como é capaz ser empregada pelo próprio ente público, ou e pelo cidadão. Conforme o artigo 70 da CF de I988, o controle da Administração Pública é classificado como externo e interno (BRASIL, I988).

O controle exterior é realizado por um poder ou entidade jurídico autônima no tocante à administração executora pela ação controlada. $\mathrm{O}$ mesmo é capaz ser realizado por meio de controle parlamentar expresso controle parlamentar ocorrido com a assistência do Tribunal de Contas da União por meio da tutela do Poder Judiciário e por intervenção da atividade popular.

O Controle Parlamentar Direto ou Político é aquele exercido diretamente pelo Congresso Nacional, ou seja, sem considerar a atuação do TCU. As competências para o seu exercício provêm da CF de 1988.

\section{CONCLUSÃO}

Para a prestação de serviços públicos o Pode Público precisa de bens duráveis como a título de exemplo livros PCs e ambulâncias Por terem sido obtidos com capital públicos, esses coisas carecem ser devidamente controlados e empregados, pois sobre os próprios reflete a primazia e a imprescindibilidade da vontade pública. 
As ações administrativas do Estado são governadas por meio de instrumentos de controle externo e interno que aspiram fazer a execução de elementos penosos à Administração Pública, especificamente a legalidade, moralidade, publicidade, impessoalidade, e a eficiência.

A administração patrimonial de bens móveis duradouros é tido uma estado de comando interno, que por atos peculiares objetiva a tutela do bem público. As áreas competentes pela administração patrimonial geram um trabalho de contabilidade focando na competência para assentar toda informação que possa influenciar o controle patrimonial, por exemplo, os movimentos conversões de responsabilização, desarranjos e transferências.

Um setor indicado ao comando patrimonial é constituído por meio da associação de regras e ações institucionais com propiciado de recursos humanos aptos e perfeitamente mensurado e com a base de tecnologias que amparem na promoção dos trabalhos.

\section{REFERÊNCIAS}

BANDEIRA DE MELLO, Celso Antônio. Curso de Direito Administrativo. São Paulo: Malheiros, 18 ed., 2005.

BRASIL. Constituição (1988). Constituição da República Federativa do Brasil. Brasília: Senado Federal, Centro Gráfico, 1988.

Lei n. I0.406, de io de janeiro de 2002. Institui o Código Civil Diário Oficial [da] República Federativa do Brasil, Brasília, DF, ir jan. 2002. Disponível em: < http://www.planalto.gov.br/ccivil_03/leis/lcp/lcpior.htm>. Acesso em:

BRASIL. Lei Complementar n. IoI, de 4 de maio de 200o. Estabelece normas de finanças públicas voltadas para a responsabilidade na gestão fiscal e dá outras providências. Diário Oficial [da] República Federativa do Brasil, Brasília, DF, o5 maio. 20oo. Disponível em: $\langle$ http://www.planalto.gov.br/ccivil_03/leis/lcp/lcpror.htm〉. Acesso em:

BRASIL. Lei n. 4.320, de 17 de março de 1964 - Estatui Normas Gerais de Direito Financeiro para elaboração e controle dos orçamentos e balanços da União, dos Estados, 
dos Municípios e do Distrito Federal. Diário Oficial [da] República Federativa do Brasil, Brasília, DF, 04 maio. 1964.

Disponível em: 〈http://www.planalto.gov.br/ccivil_03/leis/14320.htm〉. Acesso em:

BRASIL. Lei n. 8.666, de 2i de junho de 1993 - Regulamenta o art. 37, inciso XXI, da Constituição Federal, institui normas para licitações e contratos da Administração Pública e dá outras providências. Diário Oficial [da] República Federativa do Brasil, Brasília, DF, 22 jun. 1993. Disponível em: 〈http://www.planalto.gov.br/ccivil_03/leis/18666cons.htm〉. Acesso em:

BRASIL. Lei n. II.638, de 28 dezembro de 2007. Altera e revoga dispositivos da Lei n. 6.404, de 15 de dezembro de 1976, e da Lei n. 6.385, de 7 de dezembro de 1976, e estende às sociedades de grande porte disposições relativas à elaboração e divulgação de demonstrações financeiras. Diário Oficial [da] República Federativa do Brasil, Brasília, DF, 28 dez. 2007.

Disponível em: <http://www.planalto.gov.br/ccivil_03/_ato20o72010/2007/lei/lir638.htm $>$. Acesso em:

BRASIL. Superior Tribunal de Justiça. Revista Eletrônica de Jurisprudência. Súmula n. 340, DJe 13/12/1963. Ementa: "Desde a vigência do Código Civil, os bens dominicais, como os demais bens públicos, não podem ser adquiridos por usucapião.”. Disponível em: <www.stf.jus.br> Acesso em:

BRASIL. Tribunal de Justiça de Santa Catarina. Diário da Justiça Eletrônico. Apelação Cível: 0312358.93.2015.8.24.0020. Relator: Jaime Ramos. Terceira Câmara de Direito Público, DJe 14/o5/2019. Disponível em www.tjsc.jus.br Acesso em:

CARVAlHO FILHO, José dos Santos. Manual de direito administrativo. 27. ed. São Paulo: Atlas, 2013

COSTA, Rodrigo Vieira. A dimensão constitucional do patrimônio cultural: o tombamento e o registro sob a ótica dos direitos culturais. Rio de Janeiro: Lumen Juris, 2011.

DORNELlES, G. M. R. Controle interno na Administração Pública. Porto alegre. 2009. Trabalho de conclusão Gestão Pública.

DUARTE JÚNIOR, Romeu. Produção arquitetônica, cultura e patrimônio: a arquitetura cearense. Aspectos: Revista do Conselho Estadual da Cultura e do Conselho Estadual de Preservação do Patrimônio Cultural do Estado do Ceará, Fortaleza, v. 25, p. 26-35, 2006.

ELIAS, Norbert. O processo civilizador. Rio de Janeiro: Jorge Zahar, 1994. v. I 
LOPES, Miguel de Serpa. Curso de direito civil. 8. ed. Rio de Janeiro: Freitas Bastos, I996, v. 8.

KOHAMA, H. Balanços Públicos: teoria e prática. 2ª ed. São Paulo: Atlas, 2000.

TORRES, F. Jr; SILVA, L. M. A importância do controle contábil e extra contábil dos bens permanentes adquiridos pela Administração Pública Federal. Revista de

Contabilidade do Mestrado em Ciências Contábeis da UERJ, v.8, n.2, 2 
Revista Ibero- Americana de Humanidades, Ciências e Educação- REASE

open 2 access 